\title{
Thays Tonin ${ }^{1}$
}

\section{A iconologia como experiência estética. Ensaio sobre uma imagem sem fonte encontrada no Warburg Institute Photographic Collection.}

Iconology as an aesthetic experience.

Essay on an image with no sources found on Warburg Institute Photographic Collection.

L'lconologia come esperienza estetica.

Saggio a proposito di un'immagine senza fonte ritrovata al Warburg Institute Photographic Collection. 


\section{Resumo}

Este ensaio narra a experiência de pesquisa iconológica no Warburg Institute Photographic Collection, em torno de uma fotografia sem referências do acervo londrino, intitulada no artigo como "imagem sem fonte". A narrativa desenvolve-se ao redor das questões que envolvem a operação historiográfica e a experiência de pesquisa em acervos físicos e digitais, questionando-se sobre a condição da imagem e do texto como processos atravessados pela relação entre corpo e memória, logos e pathos. O ensaio parte do estudo de caso de uma imagem, e o processo de busca referencial por elementos narrativos das personificações das deusas Fortuna e Vênus, e as relações visuais que se apresentam entre ambas, principalmente depois do século XV. Levantam-se questões acerca da metodologia do historiador da arte frente à imagem, e da epistemologia da pesquisa de matriz iconológica, vista como um processo de criação narrativa e de tensões entre corpo, palavra e imagem, e portanto, como uma experiência estética. $O$ ensaio desenvolve diálogos principalmente com Aby Warburg, Edgar Wind, e Monica Centanni.

Palavras-chave: Aby Warburg. Iconologia. Arquivo. Vênus. Fortuna.

\section{Abstract}

In this essay, one narrates an iconological research experience on Warburg Institute Photographic Collection revolving around a photograph with no sources from the London collection, herein referred as "picture with no source". The narrative revolves around questions relating to the historiographical process and the research experience in digital and physical collections, inquiring about the condition of the image and the text as processes influenced by the relationship between body and memory, logos and pathos. This paper starts on the case study of an image, and the referential search for narrative elements of the personifications of the goddesses Fortuna and Venus - and of the visual relations established between them, especially after the 15th century. One raises questions about the methodology of the art historian in face of the image, and of the epistemology of an iconological research, arguing that it can be seen as a process of narrative creation and of tensions between body, word, and image - hence, as an aesthetic experience. The essay also dialogues with Aby Warburg, Edgar Wind, and Monica Centanni.

Key-words: Aby Warburg. Iconology. Archive. Venus. Fortune.

\section{Riassunto}

Questo saggio racconta l'esperienza della ricerca iconologica presso al Warburg Institute Photographic Collection, attorno a una fotografia senza riferimenti della collezione londinese, intitolata nel saggio come "immagine senza fonte". Il testo si sviluppa intorno alle domande che coinvolgono l'operazione storiografica e l'esperienza di ricerca nelle collezioni fisiche e digitali, interrogandosi sulla condizione dell'immagine e del testo come processi attraversati dal rapporto tra corpo e memoria, logos e pathos. La narrativa inizia dallo studio di un'immagine e dal processo di ricerca referenziale degli elementi narrativi delle personificazioni delle dee Fortuna e Venere, e delle relazioni visive che si manifestano tra di loro, soprattutto dopo il XV secolo. Nell'articolo vengono sollevate domande sulla metodologia dello storico dell'arte riguardo all'immagine, e sull'epistemologia della ricerca di matrice iconologica, intesa come processo di creazione narrativa e tensioni tra corpo, parola e immagine, e quindi, come esperienza estetica. Il saggio sviluppa dialoghi principalmente con Aby Warburg, Edgar Wind e Monica Centanni.

Parole-chiave: Aby Warburg. Iconologia. Archivio. Venere. Fortuna.

\footnotetext{
Pesquisadora Pós-Doutoral em Ciências Humanas pela Universidad de La Rioja (Espanha). Currículo Lattes: http://lattes.cnpq.br/1361834796813729 . ORCID: https://orcid.org/0000-0003-3912-4134 Email: toninthays@ gmail.com
} 


\section{INTRODUÇÃO}

Ao invés de postular in abstracto que existem inter-relações [entre a obra de arte singular, a teoria artística e o contexto histórico], buscá-las onde podem ser apreendidas historicamente - em objetos artísticos individuais. Ao estudarmos esse objeto concreto como condicionado pela natureza das técnicas empregadas para produzi-lo, podemos expor e verificar a validade de categorias que podem então ser úteis à estética e à filosofia da história. Este foi o critério adotado por Warburg . (WIND, 1931. p.191)²

Em 1931, Edgar Wind postulava a importância de pensar e estudar as imagens artísticas em sua unicidade, aludindo, metodologicamente, a condição de produção destas, ou seja, ao processo singular de criação de cada obra. O alemão nos reapresentava àquilo que esteve no cerne da coleção de imagens de Aby Warburg: que a pesquisa historiográfica - como processo de criação e/da narrativa - deve partir de uma imagem e/ou objeto concreto, a qual, na relação com a/o pesquisador/a, é fundadora de uma experiência estética configurada pela tensão entre corpo, palavra e imagem.

É neste sentido talvez que Warburg considerou o objeto ou imagem artística "como algo que se move de modo hostil na direção do observador"3 (WARBURG, 1890 [2011], p.205), e este "comportamento ofensivo ou defensivo diz respeito ao portador da imagem" (Ibidem). Esta experiência, portanto, é atravessada pelas relações entre corpo e memória, pathos e logos, mas também pelas regras por dentre as quais um saber se escreve e entropias a partir das quais as imagens continuam a se fazer transbordar destas regras.

Em outras palavras, reconhecendo a experiência de pensar uma imagem como uma forma de experiência estética, podemos adicionar uma segunda disposição: uma imagem nunca se encerra nela mesma, e este breve anteparo frente a unicidade da imagem rapidamente ramifica-se em tantas outras imagens quanto é possível prolongar a experiência do olhar e o desejo de (d)escrever. Neste sentido, uma só imagem pode nos levar a tantos mais tempos, espaços e linguagens que, nada mais justo do que considerá-las dinâmicas inextinguíveis, entre continuidades e variações ${ }^{4}$.

Ocorre que, se toda imagem ramifica-se de imagens que a antecipam; reivindica imagens que foram e que virão; e interpela sentidos hodiernos e também inatuais; logo, a historiografia da arte contemporânea só pode ser entendida (e escrita) enquanto narrativas desta trama de imagens e suas densidades formais e camadas discursivas, onde, mesmo a contragosto, ouviremos continuamente, como um rumor, as palavras de Eco: "toda história conta uma história já contada". (ECO, 1985, p.20)

É desta forma que o conceito de experiência estética se mostra fortuitamente necessário. A experiência com a imagem se coloca como um ato estético, como um acontecimento performativo e capaz de transportar valores éticos, e a imagem como uma autopoiesis em contínua produção de sentidos.

\footnotetext{
2 [Tradução da autora].

3 [Tradução da autora].

4 Não à toa, estas palavras intitulam uma Lecture de Fritz Saxl poucos anos depois no The Warburg Institute, a saber: SAXL, Fritz. "Continuity and variation in the meaning of images" (1947) (SAXL, 1957).
} 
Podemos, por fim, somar a tal compreensão de movimento da imagem, a dinâmica que perdeu a atenção dos historiadores da arte atualmente (em detrimento da dinâmica que uma imagem pode vir a criar fora de sua existência concreta): a saber, que estas imagens são, antes de tudo, formas físicas em arquivos, museus, coleções, ruas, casas e ateliês. A primeira questão metodológica levantada aqui é a de que tais objetos de pesquisa fazem parte de acervos públicos e privados, de reservas técnicas esquecidas, de coleções empilhadas, de locais perdidos, antes de fazerem parte de repositórios virtuais. Pesquisar uma imagem e suas dinâmicas, desta maneira, é também pesquisar os locais que a arquivaram, e as maneiras pelas quais o objeto físico chegou (ou não) a nós hoje - e não só a sua virtualidade.

\section{ICONOFILIA}

Em consequência, este ensaio relata a operação narrativa de pensar acerca da imagem, de compreender a experiência de pesquisa do(a) historiador(a) como parte imanente da história narrada, assim, apresentando-a como uma experiência conduzida entre lugares e virtualidades, entre palavras e imagens, tradições e contribuições, formas e conteúdos, e ainda, entre o "fazer artístico" e "fazer historiográfico".

Se por um lado argumenta-se que esse processo de escrever (e pensar) o objeto é uma experiência entre linguagens, também se pode considerar que, perante as imagens, existe uma forma de experiência iconofílica - ou seja, de ser afetado pelas imagens, sob várias maneiras e em vários níveis sensoriais-cognitivos. Não se demora sobre uma imagem sem que esta afete, transfira, possua.

Consequentemente, o que afeta qualquer pesquisador de uma única imagem para conduzir uma narrativa é, entre outras coisas, a experiência - entre a filia e a logia - de buscar mapear as transmigrações da imagem que amalgama elementos figurativos interpretáveis e ausência de informações sobre suas fontes. É em meio a esta "imersão amorosa dos dados empíricos" (NIETZSCHE, 2003, p.55), que a imagem declara a sua contemporaneidade para com o/a pesquisador/a, antes mesmo de declarar seu nascimento.

Derivam destas compreensões (de imagem, de operação historiográfica, de pesquisador/a) o modo de construir os caminhos da narrativa a seguir, ensaiando motivos pelos quais a imagem (figura 3) encontra-se onde está, e, como se fez encontrar, entre tantas outras. 


\section{ACEDER À IMAGEM:}

\section{THE WARBURG INSTITUTE PHOTOGRAPHIC COLLECTION}

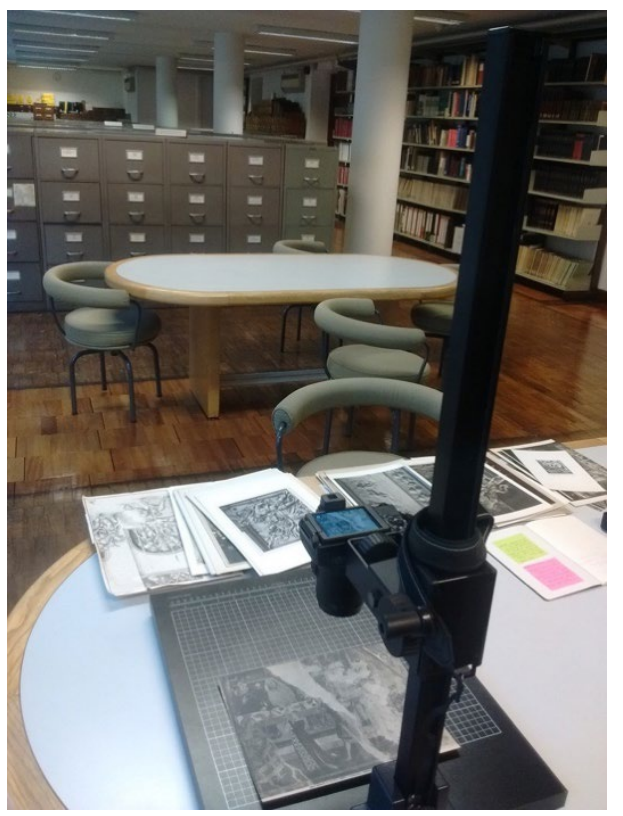

Figura 1. Os arquivos físicos do The Warburg Institute Photographic Collection. Fonte: Arquivo Pessoal, 2016.

A imagem que dá início à reflexão deste ensaio é uma fotografia integrante da Coleção do Instituto Warburg (The Warburg Institute Photographic Collection) (figura 1). A coleção pode ser definida como um arquivo físico (e, futuramente, também virtual) do repertório de temas de estudos da tradição clássica e de uma percepção de memória social ocidental(izada) $)^{5}$. 0 fato, aparentemente simples, desta imagem ser parte do arquivo londrino é um dos pontos de partida para a presente reflexão, visto que este se configura como um repertório sem paralelos, que soma atualmente 400.000 fotografias (entre imagens de esculturas, pinturas, desenhos, impressões, tapeçarias, gravuras, manuscritos iluminados, book plates e outras formas). A variedade de objetos fotografados demonstra, de facto, tanto a compreensão de Aby Warburg sobre a relação inerente entre arte e cultura, palavra e imagem, quanto também a complexidade em estabelecer em um arquivo as imagens físicas desta relação, sob categorias temáticas e palavras-chave ("catch-word").

Embora a sua taxonomia baseada em temas iconográficos e motifs artísticos torne flexível e modificável o lugar onde essas imagens se encontrariam (consentindo assim uma possível dinâmica das categorizações figurativas), alguns consensos iconográficos ao longo dos estudos histórico-artísticos formam uma estrutura-base na coleção. Dentre estes estudos, ao longo das décadas de existência do instituto, podemos destacar principalmente aqueles provindos dos trabalhos de $\mathrm{F}$. Saxl, E. Panofsky, E. H. Gombrich e, como se imagina, das próprias divisões criadas por Warburg em Hamburgo, a qual permanece na mesma lógica (figura 2). 


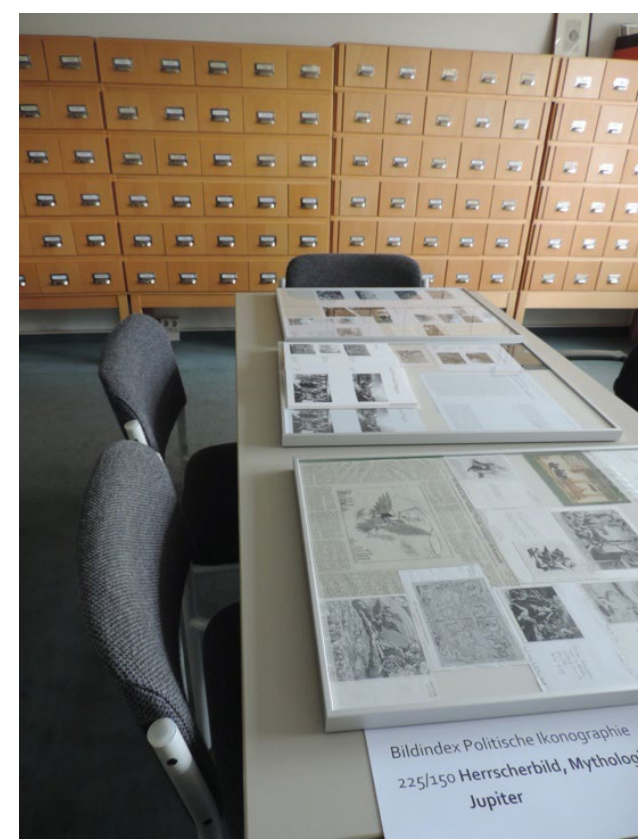

Figura 2. Coleção do Instituto Alemão, "Waburg Haus". Fonte: Arquivo Pessoal, 2016.

Já no que diz respeito à quantidade de registros, à variabilidade de fontes, à amplitude de procedências das imagens (nas temáticas de simbolismos geográficos-temporais e dos sincretismos da iconografia clássica), resulta perceptível que, nos últimos anos, o instituto continua a acumular novas documentações - provindas de doações diversas, de museus, de pesquisadores/as, etc. Tal postura revela o interesse do instituto em que seus pesquisadores continuem a rever e arriscar-se por novos desdobramentos acerca das fontes que ali se encontram. Nota-se também que a dificuldade, logo, de um pesquisador que trabalha com a transmissão de um tema iconográfico ao longo dos séculos diminuiu, e tal condição se apresenta mediante a instauração do acervo virtual da instituição, e de repositórios online de livros raros das Universidades como a de Londres, ambos alimentados constantemente de novos arquivos para investigação.

Como exemplo da amplitude deste acervo virtual, encontra-se facilmente mais de 1000 resultados com a catch-word Fortuna, as quais são distribuídas entre pastas subdivididas por marcadores iconográficos, a saber: pela imagem da deusa na presença de outros personagens, na presença de elementos acessórios e narrativos ou ainda, como figura secundária em representações de macrocosmos. O tema da Deusa Fortuna, deste modo, é desmembrado em mais de 20 subdivisões (pastas físicas e virtuais) relativas a categorias da iconografia tradicional ou relativas a elementos menos e mais comuns ao tema6.

A escolha da aqui intitulada "imagem sem fonte" como objeto deste ensaio (figura 3) surgiu logo após um procedimento de pesquisa que se constituiu em fotografar mais de 400 registros encontrados nas pastas que se referem a Fortuna, notando, assim, uma hibridização de interpretações iconológicas entre os elementos que compõem o tema da deusa com elementos que irão constituir o tema de outros

$6 \quad$ O Subject Index usado como exemplo encontra-se disponível no site do instituto. Link de acesso: HYPERLINK "file:///C:IUserslthaystonin|Desktopl\%20https:Iwarburg.sas.ac.uklcollections/photographic-collectionlsubject-index" https://warburg.sas.ac.uk/collections/photographic-collection/subject-index. Acesso em: 28/02/2021. 
personagens clássicos, como Kairós, Ananke, Tyché e Vênus.

Uma vez que o Arquivo de fotografias per se desempenha um papel na hipótese final da trajetória desta imagem, é relevante lembrar que o trabalho de pesquisa em arquivo - como no caso da coleção do instituto, entre as 18.000 pastas temáticas

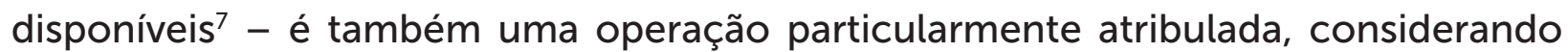
que a investigação depende da experiência presencial, ou seja, do processo de separar gaveta por gaveta, pasta por pasta, imagem por imagem. Além disso, deve-se salientar que o database virtual constitui somente $20 \%$ das imagens presentes no espaço físico da coleção ${ }^{8}$. Desta forma, a pesquisa iconológica constituída a partir do arquivo mostra uma raiz metodológica ainda presente, uma importância no estudo do aspecto quantitativo de análise do tema, buscando valores representativos de elementos acessórios em recortes específicos de tempo. O processo de pesquisa, à visto disto, depende também de um trabalho investigativo de média a longa duração, e, muitas vezes, dependerá igualmente da busca por referências em outros arquivos e acervos.

Enfim, tal é o caso da "imagem sem fonte" (figura 3), encontrada na coleção fotográfica em setembro de 2016, sob a categoria "Fortune" (Fortuna), e na subdivisão "with atributes" - "Sail or veil".

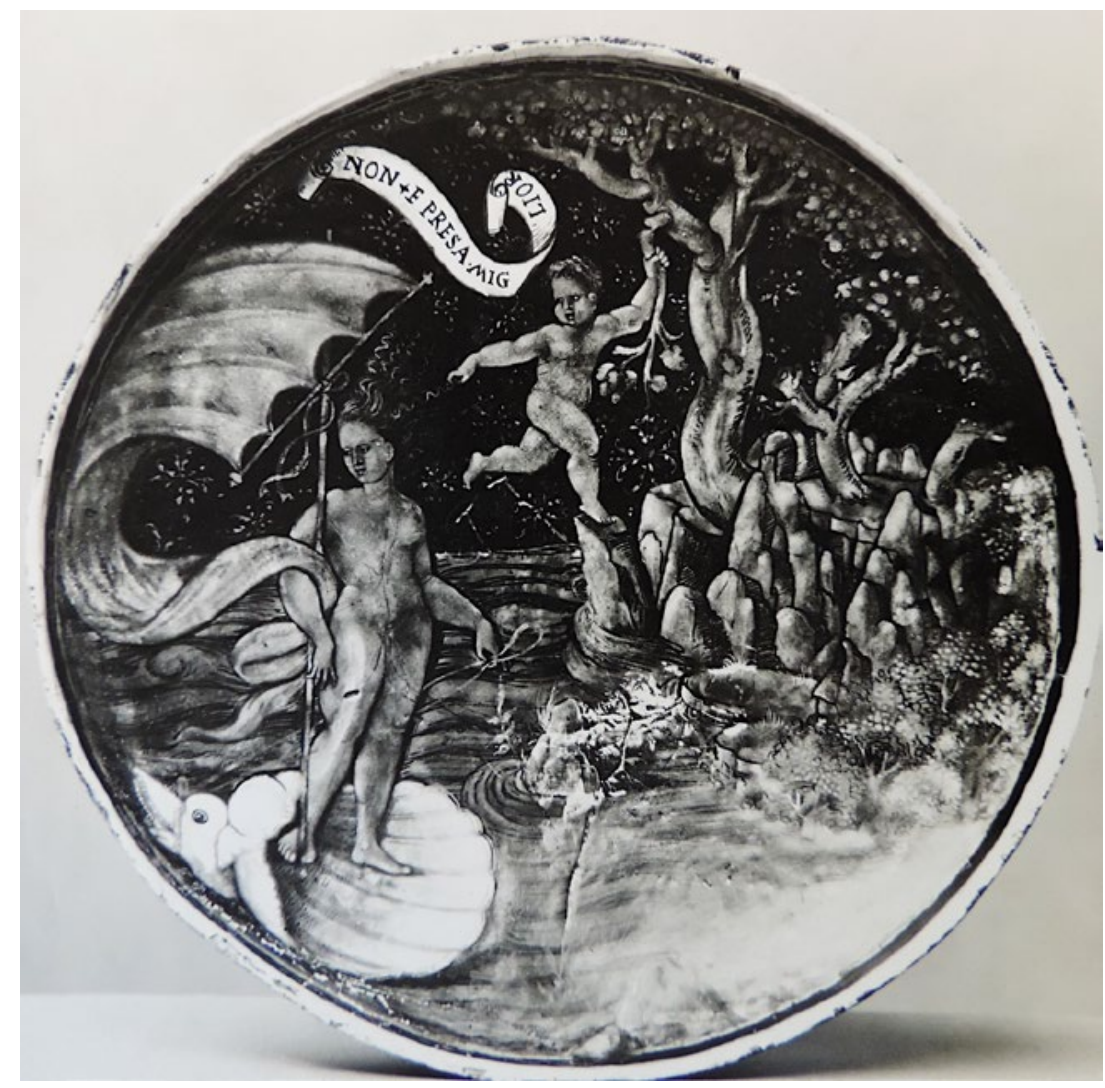

Figura 3. Imagem sem fonte. Reprodução de arquivo pessoal, set, 2016. Copyright: @ The Warburg Institute Photographic Collection.

7 Cfr. a descrição da Photographic Collection no site do Instituto. Link de acesso: https://warburg.sas.ac.uk/library-collections/photographic-collection Acesso em: 28/02/2021.

$8 \quad$ Para acessar o acervo virtual: Iconographic Database. The Warburg Institute Iconographic Database. Link: https://iconographic.warburg.sas.ac.uk/ vpc/VPC_search/main_page.php. Acesso em: 28/02/2021. Este será citado a partir de agora como DATABASE, 2021. 
A fotografia não apresentava no seu verso nem a fonte da imagem (ou do objeto), nem a autoria da obra, diferentemente da maioria das imagens presentes nos arquivos do instituto, onde encontramos referências manuscritas ou datilografadas no verso do documento.

A imagem trouxe apenas a categoria "ícone secular" como sua identificação de tema iconográfico (figura 4), além de esparsas e incertas anotações à caneta com indicativos de material, data e local de produção da obra. Iniciou-se a busca, portanto, na ausência de uma ficha técnica ou legenda iconográfica da imagem do ornamento encontrado.

C.72- 1939

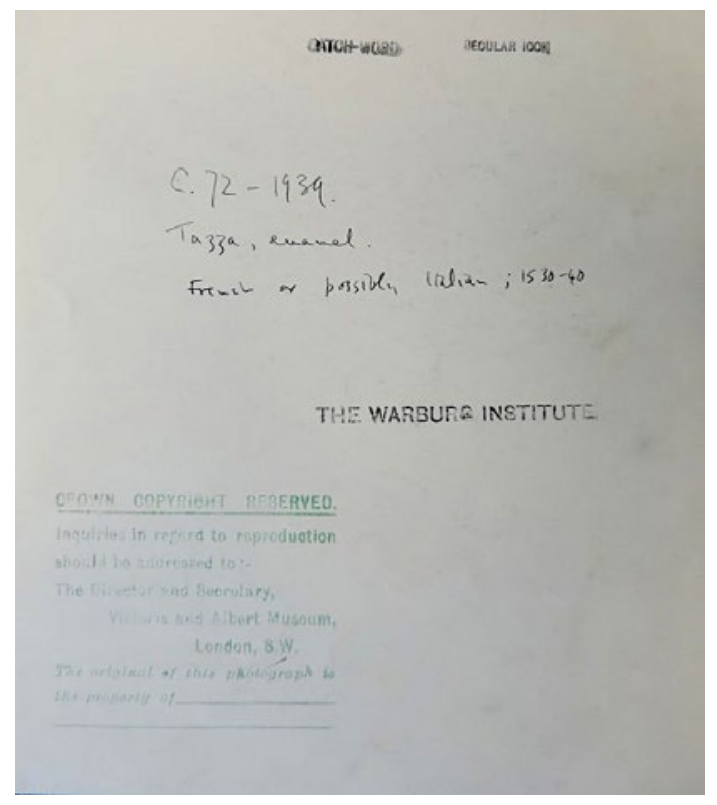

CATCH-WORD SECULARICON

TAZZA, ENAMEL.

FRENCH OR POSSIBLE ITALIAN ; 1530-40

COPYRIGHT RESERVED.

THE WARBURG INSTITUTE

INQUIRIES IN REGARD TO REPRODUCTION

SHOULD BE ADDRESSED TO :-

THE DIRECTOR AND SECRETARY,

VICTORIA AND ALBERT MUSEUM,

LONDON, 8.W.

THE ORIGINAL OF THIS PHOTOGRAPH IS

THE PROPERTY OF

Figura 4. Verso da fotografia. Arquivo pessoal, setembro 2016. Fonte: @ The Warburg Institute Photographic Collection, Londres.

Assim, como descrito na misteriosa legenda, trata-se de uma fotografia de um esmalte (Enamel), possivelmente o interior de uma Tazza (ornamento de mesa) vista de cima, criada no século XVI - sem localização geográfica precisa, ou autoria. A última informação disponível é uma data, "1939", que poderia referir-se à data em que 
foi adquirida pelo instituto ou catalogada na coleção do Victoria and Albert Museum (V\&A Museum), o que resultaria em caminhos distintos de pesquisa.

Em contato com o acervo do museu, compreendeu-se que as informações presentes no verso da fotografia eram uma reprodução das informações providas pelo V\&A Museum, sem nenhum adendo feito pelo instituto.

No museu, encontrou-se a seguinte descrição:

\section{OBJECT DETAILS}

OBJECT TYPE: Dish, 16h century (made) - Not currently on display at the V\&A BRIEF DESCRIPTION: Limoges enamel on copper, ca.1540

DIMENSIONS: Diameter: $19.5 \mathrm{~cm}$ (Note: Measured) MARKS AND INSCRIPTIONS: 'NON + E PRESA · MIGLIOR' (On scroll, inside tazza) CREDIT LINE: Purchased through the John Webb Trust OBJECT HISTORY: Purchased from Messrs Stola (through the John Webb Trust) COLLECTION: Ceramics Collection ACCESSION NUMBER: C.72-1939 RECORD URL: https://collections.vam.ac.uk/item/O344646/dish/

Além disso, no acervo, as imagens do ornamento também não apresentavam uma legenda completa ou ficha técnica, todavia, estavam disponíveis outras 4 fotografias de interesse para este ensaio (figura 5): 


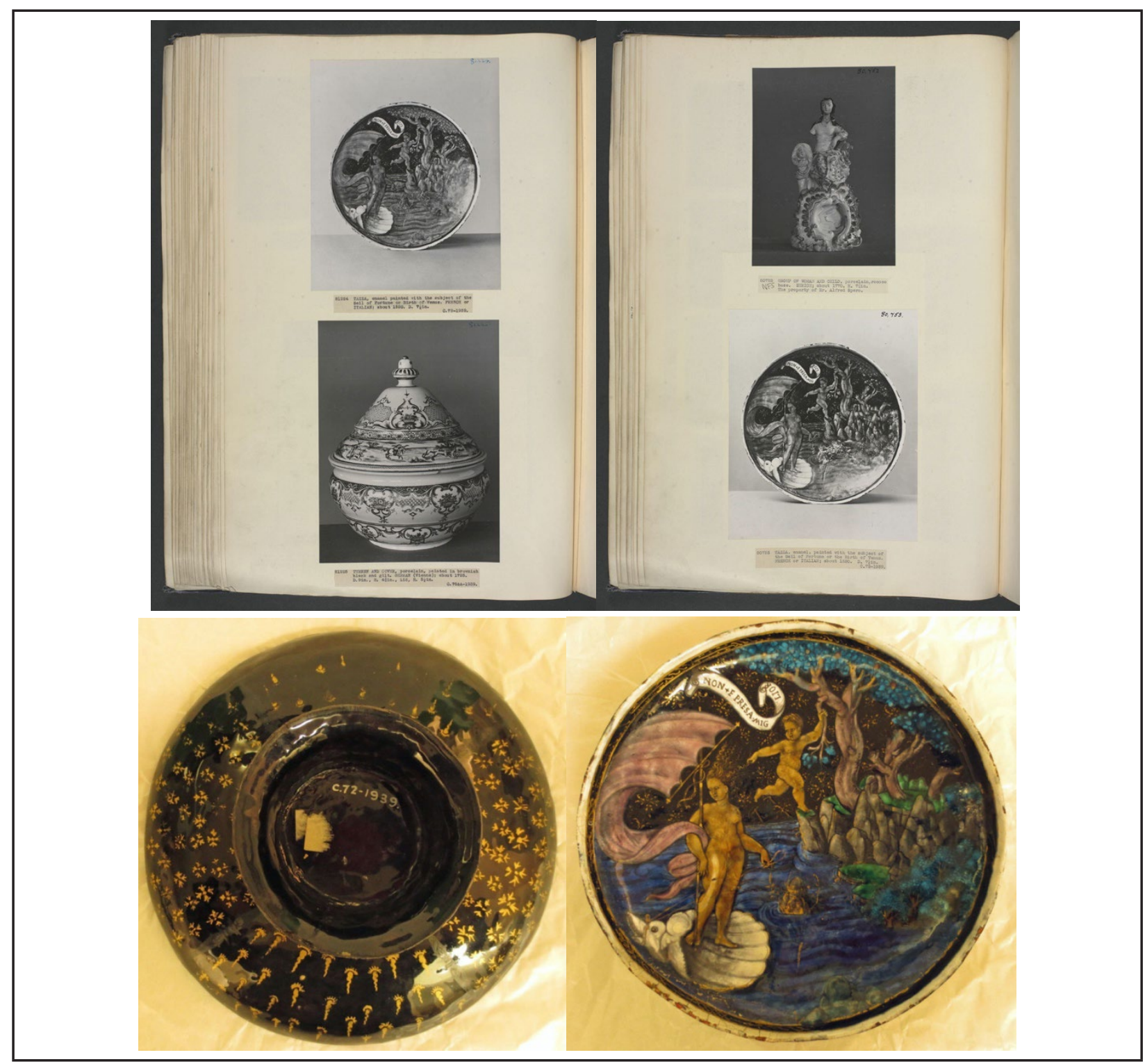

Figura 5. Montagem com as 4 imagens disponíveis na coleção do V\&A Museum. Fonte: @ Victoria \& Albert Museum Collection.

Diferentemente da legenda atual das fotografias, vemos que nas imagens do antigo catálogo físico encontra-se uma primeira e breve descrição iconográfica: "painted with the subject of the Sail of Fortune or the Birth of Venus" (figura 5). Esta curiosa relação entre os temas da personificação da Fortuna e de Vênus só poderá ser entendida a partir de um deslocamento geográfico, quando aparecerão elementos narrativos em comum para as deusas. Retomarei esta questão a seguir.

Retomando a figura 3, é possível identificar os primeiros elementos simbólicos na composição, são eles: a vela em tecido amarrada ao bastão, a concha aos pés da figura feminina nua, o cisne à sua esquerda, contido pela corda que se encontra na mão esquerda da personagem, e a criança nua que agarra o cabelo da figura feminina com uma das mãos, enquanto a outra se agarra a uma árvore. A jovem figura, por sua vez, que chega do mar na orla de uma região montanhosa tem nas mãos dois objetos importantes: de um lado a vela de um barco, e do outro um laço, uma rédea, que segura o encilhamento do cisne no mar. Mesmo o vento que sopra em direção 
ao mar se destaca como um elemento iconográfico a ser levantado neste primeiro momento. O movimento do vento como componente é apresentado por Warburg e retomado por Didi-Huberman (2015) com o conceito de "brise imaginaire", e serve para demonstrar uma fórmula de movimento presente nas obras.

Ocorre que os temas retratados na imagem sobre a qual este ensaio se ocupa, pertencem à tradição clássica, a qual é compreendida como um corpus literário, simbólico e iconográfico, ou ainda, consiste em um "thesaurus em contínuo incremento e reformulação"9 (CENTANNI, 2005, p.9). Dito de outra forma, a tradição clássica é pensada como um repertório entre palavras e imagens que tem por condição "um processo dinâmico de transmissão que prevê desde a alteração, a reinterpretação, a reinvenção e o equívoco (voluntário ou involuntário), até, por fim, a traição dos conteúdos e das formas"10 (Ibidem, p.3). Neste sentido, o reconhecimento das figuras como Fortuna e/ou Vênus provém de uma tradição de tratados de descrição, textos literários e objetos artísticos - ou seja, este corpus que inclui grandes obras enciclopédicas, as quais inventariaram as diferentes descrições, imagens, alegorias, metáforas e símbolos presentes nas artes.

Este repertório de descrições chega a nós nos dias de hoje como uma herança literária e de emblematas, iluminuras e tratados de história, técnica e forma, oriundos de diferentes séculos antes da era cristã, como a Hieroglyphica de Orapollo (V-IVaC), Metamorfoses de Ovídio (VIII aC), Teogonia de Esiodo (VII aC) os manuscritos intitulados Aratea (XV aC - XIX dC), a Saturnalia de Macrobius (IV dC), a De Consolatio Philosophiæ de Boezio ( $\mathrm{VI} \mathrm{dC}$ ), até os compêndios modernos, Liber compilationis physiognomiae, Breviários, Manuais e Tratados de iconologia ${ }^{11}$, como os de Cesare Ripa e Andrea Alciati. Seria impossível elencar cronologicamente todos os textos que fazem parte desta tradição aqui. Contudo, como deve acontecer com o estudo de qualquer tema da tradição clássica, essa pesquisa filológica deve ser levada em consideração.

Destarte, o percurso da experiência de pesquisa mediante o acervo londrino começa por entender quais descrições iconográficas desta tradição foram levadas em consideração em quaisquer dos documentos encontrados sobre a Tazza em Esmalte.

Dadas as indicações presentes na figura 4 sobre a procedência da Tazza, pode-se supor que primeiras tentativas de busca pela fonte da imagem limitaram-se aos documentos em lingua italiana, francesa ou inglesa (figura 2), inquirindo possíveis estudos de caso da obra ou referências primárias. Em outros termos, a experiência em torno desta imagem relembrando-nos do papel ativo da linguagem, da tradução e das estruturas linguísticas na operação historiográfica. Contudo, visto que o contexto inglês assim como franco-italiano foi insuficiente para traçar qualquer momento da migração dessa imagem até o repertório do Instituto Warburg, a pesquisa passou

\footnotetext{
9 [tradução da autora].

10 [tradução da autora].

11 Jean Seznec, em seus ensaios de 1981, compilou um importante elenco de "bíblias dos símbolos" (p.281), como irá chamar, da tradição antiga e arte medieval ao renascimento (SEZNEC, 2015).

Além de Seznec, Roelof van Straten, em seu livro de 1985, compilou os manuais de iconografia modernos até o virtual ICONCLASS, que serviram aos artistas e estudiosos como coleções de reproduções e fontes fundamentais de pesquisa (VAN STRATEN, 2009).
} 
a incorporar acervos virtuais espanhóis e portugueses, não por quaisquer relações indiciárias, mas por aproximação e limitações linguísticas.

As primeiras correlações entre a imagem e suas descrições por escrito surgiram dos improváveis resultados da busca em língua portuguesa, mediante traduções e troca de categorias. A busca por fontes também teve ramificações para além dos acervos permanentes de museus, catálogos virtuais e livros publicados - relembrando, deste modo, os caminhos possíveis dos objetos artísticos desde os grandes palácios e nobres casas, até seu reconhecimento como objeto de rememoração e, portanto, museificável.

Assim, pesquisando nos arquivos históricos e literários das bibliotecas lusitanas, surge por fim uma correlação entre a fotografia do Instituto e uma descrição em português de um objeto - encontrada no Arco da Biblioteca Nacional de Portugal. A fonte, contudo, é a narrativa em português palaciano de um romancista português do século XIX. É nos escritos epistolares de Carlos Malheiros Dias (1875-1941), entre as prosas da coleção intitulada "Cartas de Lisboa" publicada em 1905, que temos uma das primeiras descrições da imagem do esmalte catalogada no Instituto Warburg.

O fato que levou Dias a descrever a existência destes ornamentos colecionáveis expostos em um palácio português próximo a Lisboa, bem como as narrativas neles representadas, parece, em primeiro lugar, servir para delinear os objetos como exemplo do mais estimado "capital cultural" de um milieu lusitano, de considerável circulação. Em segundo lugar, suas cartas parecem propor um interesse conservacionista relacionado ao valor das coleções presentes em Portugal no seu conjunto, como um reconhecimento face às outras grandes coleções de patrimônio artístico da Europa.

Foi, assim, Carlos Malheiros Dias, famoso em terras brasileiras pelo seu romance naturalista $A$ Mulata, de 1896, que em português áulico forneceu uma das primeiras descrições da imagem em jogo, e a primeira referência catalográfica portuguesa.

Dias disponibiliza ao leitor praticamente um catálogo dos objetos decorativos das vilas e palácios portugueses que acolheram eventos sociais e artísticos durante a virada do século XX. Descrevendo nas cartas as coleções de arte portuguesa entre os séculos XVIII e XIX como apetrechos de nobreza, Dias expôs uma parte importante da história da coleção lusitana que reflete um "impulso colecionador" em relação ao esmalte medieval e renascentista em Portugal, cujo movimento ainda não foi exaustivamente analisado pela própria historiografia portuguesa (SANTOS, 2016, p.76).

A descrição feita pelo romancista trouxe consigo não apenas escolhas estilísticas de um ensaísta que narra em um específico gênero textual, mas também acabam por envolver dois outros aspectos de sua escrita: a da formação como historiador, que deixa transparecer o desejo de construir uma narrativa iconográfica dos objetos-símbolos em terras portuguesas, validando uma lógica cultural europeia. Como historiador, por fim, Dias referencia seu texto a partir do primeiro catálogo conhecido da Coleção Palmella, de autoria de Gabriel Pereira em 1902.

Os documentos portugueses que serão apresentados a seguir foram descobertos a partir das cartas de Dias, e apresentam uma legenda iconográfica do esmalte do Cinquecento, nomeadamente: Os Esmaltes da Casa Palmela (PEREIRA, 1902), Cartas de Lisboa (DIAS, 1905), a Exposição de 1822 (CATÁLOGO ILUSTRADO, 1822) e as listas da tese de Santos (SANTOS, 2016). 


\section{A VÊNUS E O CUPIDO, OU A LEITURA PORTUGUESA}

Nos escritos de Carlos Dias, alguns elementos do colecionismo das famílias nobres em Portugal são brevemente descritos, ou nas suas palavras, "à vida elegante das altas classes" (DIAS, 1905, s.n.). As cartas foram publicadas em duas edições de contos, que eram tratadas pelo autor como "a mais escandalosa chronica de costumes com que poderia sonhar a fantasia ambiciosa de um chronista inconfidente e sem escrúpulos!" (Ibidem, 1905, s.n.).

Em Cartas de Lisboa vemos uma crônica sobre a Casa Palmella, "uma casa, que a todas as da côrte e do reino sobreleva em categoria e esplendor, depois dos paços reaes, e que justamente logrou fama de abrigar os mais esplendidos thesouros de arte", os quais foram descritos no catálogo da Galeria do Calhariz, sob o título de "Catalogo dos quadros e mais objetos de Bellas-Artes, que se acham no palacio do duque de Palmella" (DIAS, 1905, p.29).

A exposição em questão tinha uma sessão de Louça Antiga denominada de Leão X (Ibidem, p.29), e em seu catálogo descrevia-se uma retrospectiva das artes ornamentais de 1882 que pertenceu aos duques de Palmella e outras casas nobres. A Casa Palmella da família "d'essa nobre casta do patriciado romano" (Ibidem, p.33-34), exibia o que foi descrito como o mais

luminoso documento d'esse secular cultivo das artes, a resultante do gosto esmerado de gerações successivas, como as collecções dos Urbinos, dos Malatesta e dos Médicis, reunidas pela munificencia das familias principescas de italia, protectoras das bellas-artes e principaes instigadores da Renascença. (Ibidem, p.35-36).

A coleção de vinte e cinco esmaltes de Limoges ${ }^{12}$, que no catálogo da Calhariz se chama "louça antiga de Leão X", se refere a coleção do Papa Leão X, nascido Giovanni di Lorenzo de 'Medici, em Florença, no ano de 1475, segundo filho de Lorenzo de 'Medici (Lorenzo il Magnifico).

A coleção foi provavelmente trazida de Roma para Portugal no final do século XVIII para a Casa de Angeja quando adquirida pelo 1을 Duque de Palmella segundo os escritos de Dias. O escritor avisa não poder afirmar com certeza se o nome dado à coleção de Limoges fazia parte da coleção do Papa Leão X no Palazzo Madama em Roma - ainda que a coleção contenha obras do período áureo de Limoges - ou se o nome havia sido dado à coleção sugerindo a hipótese deste ter sido reunida tal como "se encontra ainda hoje, por um amador opulento do século XVI [...] não porque ella tivesse feito parte dos tesouros artísticos de Leão X [...] mas porque, à similhança de Pericles, ele legou o seu nome ao seu seculo." (Ibidem, p.46).

Contudo, como o próprio escritor ainda pontua, a Coleção Palmella agora contém os mais preciosos exemplares de esmaltes antigos existentes em Portugal (Ibi-

12 O Esmalte de Limoges (região sudoeste da França) é caracterizado por métodos de coloração metálicos de objetos decorativos que se remete a sobrevivência de tradições técnicas medievais e renascimentais, do Champlevé, ao Grisaille, (século XII - XVIII). As temáticas variavam no decorrer dos séculos, das cenas cavalheirescas às narrativas religiosas e mitologia clássica. Variavam também as composições de ornamentos, os quais mereceriam um artigo à parte. Importante pontuar, por fim, que os laboratórios ou estúdios de esmalte eram privilégios reais, e portanto, mantidos por gerações de famílias. Não à toa os esmaltes serão considerados objetos de grande valor cultural na Europa. 
dem, p.43), e expõe os temas prediletos dos esmaltadores de Limoges, ou seja, as composições em voga na Itália do século 15 ao 16. Fato é que a coleção, diz ainda Dias, "não diferindo sensivelmente do estylo das restantes peças o fructeiro assignado Pierre Nouailher e a bandeja assignada Jean Laudin, que vejo no catalogo da exposição de 1882 classificados como do século XVII, quando é certo existirem já no seculo anterior Nouailhers e Laudins esmaltistas em Limoges" (Ibidem, p.46).

A coleção, que parece datar inteiramente do século XVI, inclui as obras dos famosos ateliês e artistas limonginos, como Jean Courteys (ou Court, séc XVI circa), Pierre Reymond (1513-1584), entre outras "dinastias", como as geraões das famílias Nouailher e Laudin, expoentes do Milieu du XVle de Limoges. Além disso, a coleção Palmella incluía outras seis "taças de pé" (ibidem, p.46), reconhecidas desde o Catálogo de 1822 como esmaltes de Limoges, que Dias acredita certamente transportaram os temas preferidos da pintura italiana "desde Botticelli e Donatello até Raphael e Miguel Angelo “(ibidem, p.47), retomando sua afirmação de que o apogeu do esmalte de Limoges foi inspirado entre outras coisas nas gravuras alemãs e Renascimento italiano, visto que as composições dos grandes mestres das escolas de Florença e Bolonha foram reproduzidas no esmalte.

Era sobretudo á pintura italiana que os esmaltadores de Limoges iam buscar os seus themas predilectos. Na collecção Palmella esse facto mais uma vez se verifica. A época é maravilhosamente caracterizada pela aliança, em quasi todas as composições, do assumpto sacro e do assumpto mythologico. (Ibidem).

A leitura interpretativa feita por Dias das cenas narradas nas cerâmicas remonta, portanto, às obras que o historiador acreditou influenciar os esmaltes da coleção, bem como ao que chamou de "pressupostos sagrados e mitológicos" característicos da pintura italiana a partir do século XV. É assim que a descrição do Esmalte (figura 3)que vemos na fotografia do repertório de imagens do Instituto Warburg - é referida como uma fruteira em esmalte chiaro-scuro e dourado, onde o infante, interpretado como "cupido", aparece segurando o cabelo da figura feminina, interpretada como Vênus seminua, a qual navega em uma concha de madrepérola, guiando pelas rédeas um cisne, e com a vela "levada pelo vento". Dias também descreveu toda a coleção de taças e fruteiras da qual afirma fazer parte a nossa figura 3, e que representariam seis cenas-temas da tradição clássica.

E è assim que n'um fructeiro, em esmalte claro-escuro e ouro se vê o julgamento de París; n'outro David explicando os psalmos; ou ainda, sob a divisa Non e presa miglior, um Cupido prende pelos cabelos uma Venus semi-núa, que navega n'uma concha de nacar com a vela enfunada, [...] a destruição de Sodoma e a sahida de Rabeca da casa paterna; a batalha dos israelitas e amalecitas, Adão e Eva colhendo o pomo prohibido, a expulsão do Paraizo" (lbidem).

Todavia, ao contrário dos outros esmaltes aos quais se refere pelo nome do artista a quem a obra é atribuída, nesta coleção de taças a falta da "assinatura" nos or- 
namentos não parece ser importante - seja o autor ou data da fatura - assumindo-se assim que os esmaltes estavam ao nível dos restantes que compõem a coleção Palmella e pertencentes aos esmaltadores e à Maneira Limoges do século XVI.

Outra descrição que temos do esmalte é a do Catálogo Ilustrado da Exposição Retrospectiva de Arte Ornamental Portuguesa e Hespanhola, de 1882 em Lisboa que, aliás, é uma cópia da descrição feita por Pereira em 1902 (Pereira, 1902, 4 - 5). Toda a coleção foi exposta no Salão L, e o catálogo descreve o esmalte como:

28. Fructeiro. Em cobre esmaltado de Limoges. Tem pintada no fundo Venus navegando n'uma concha com a véla larga e de um rochedo Cupido, segurando-se ao tronco de uma árvore, agarra-a pelos cabelos; por cima a legenda: NON+E PRESA MIGLIOR. Diam. 0,19. Srs. Duques de Palmella, Lisboa. (CATALOGO ILUSTRADO, 1822, p.225)

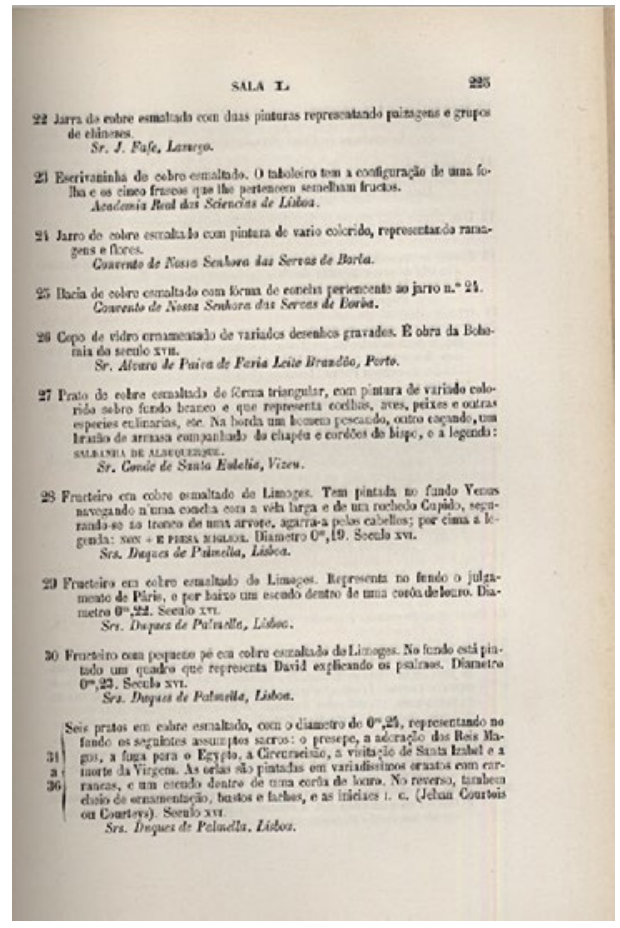

Figura 6. Pagina 225 do Catálogo da Exposição Retrospectiva de Arte Ornamental Portugueza e Hespeanhola. Biblioteca Nacional de Portugal.

Logo, nas únicas referências portuguesas atribuíveis ao esmalte em questão, vemos que a leitura iconográfica mantém-se como aquela onde as figuras humanas representam Vénus e Cupido (Amor) - tanto no livro comemorativo de Pereira (1902), no Catálogo de 1822, como no escritos de Dias em 1905, e na análise crítica de Santos sobre colecionáveis portugueses em 2016³. Esta escolha, como tentou-se

\footnotetext{
13 A saber: "No final da década de 1530, começam a surgir peças de baixela de aparato em cobre esmaltado pintadas na técnica de grisaille, dirigidas, por natureza, a uma clientela abastada e de gosto requintado, a mesma da prestigiada faiança italiana cujo mercado por certo partilhou. A constituição destas baixelas, que frequentemente nos surgem armoriadas (ainda que as armas permaneçam por identificar) obedecia aparentemente a programas iconográficos de alguma complexidade com temáticas muito estimadas pela literatura e pelas artes plásticas deste período (designadamente pela gravura, que continuou a ser a fonte primordial), como Amor e Psiché, Orfeu, combates de cavaleiros, ou alegorias dos meses do ano e servia um gosto que se adivinha ilustrado e próximo da corte. [...] As gravuras alemãs e italianas foram a fonte preferencial dos esmaltadores deste período, constituindo o seu ponto de contacto com a vanguarda da arte renascentista". (SANTOS, 2016. p.278). Assim, o argumento destacado por Dias sobre a importância de artistas florentinos como Botticelli não é acidental, logo, sua interpretação iconográfica da figura feminina como Vênus - atribui-se, entre outras coisas, aos elementos da pintura criada para a Villa Medicea di Castello, "La Nascita di Venere" (1485-1486)
} 
demonstrar, para o início do século XIX, deve-se aos elementos iconográficos comumente reconhecidos como acessórios narrativos da Deusa Vênus. Provindos das narrativas canônicas, como Hesíodo, Ovídio, Homero e Dante, ou da herança clássica apresentada previamente, Vênus é frequentemente aludida na presença de maçãs de ouro, com a concha que a porta das espumas do mar (da qual é nascida), ou ainda, de uma carruagem puxada por cisnes ou pombas. Além disso, outros elementos como a presença de um infante - Eros e sua flecha, ou ainda, Adonis e a árvore em que foi transformada Mirra -, aparecerão em obras que carregam consigo a narrativa de Ovídio, em Metamorfoses (MUELA, 2000, p.29-30).

Entre 1548 e 1556 três manuais italianos ganham espaço na figuração de Vênus, a partir dos escritos de algumas grandes figuras do humanismo. Baseados em textos previamente citados e também em obras como $O$ asno de ouro de Apuleio, e De signis de Porfirio, os mitógrafos Giraldi e Cartari constroem repertórios dos elementos descritivos de deuses pagãos, trazendo fragmentos de mitos celtas e germânicos. É a partir de seus escritos que se reconhecem com mais amplitude outros caminhos iconográficos de Vênus, como retoma Seznec, acerca da "Venere Sassone" (SEZNEC, 2015, p.275-282) (figura 7) ${ }^{14}$ :

Agora, a história desta Vênus "saxônica" é tão intrincada quanto instrutiva e, portanto, merece ser reconstituída. Na verdade, a Cronaca di Bote chega até 1489 e foi publicada pela primeira vez por Peter Schoeffer em Mainz em 1492, acompanhada de numerosas gravuras.

No entanto, uma descrição desta Vênus já pode ser lida em Mer des hystoires, uma crônica francesa impressa em Paris por Pierre le Rouge em 1488 que contém vários capítulos sobre os deuses (capítulos 11-60): "Segundo Teotecto, o simulacro "a imagem de Vênus" eram aqueles de uma mulher nua de aspecto amável, os cabelos soltos sobre os ombros, na cabeça uma coroa de murta entrelaçada com rosas vermelhas; em seu coração, uma facella, ou pequena luz ardente, e uma flecha tripla. À esquerda ela tinha o mundo dividido em três partes, céu, terra e mar, à direita, três maçãs de ouro ${ }^{15}$.

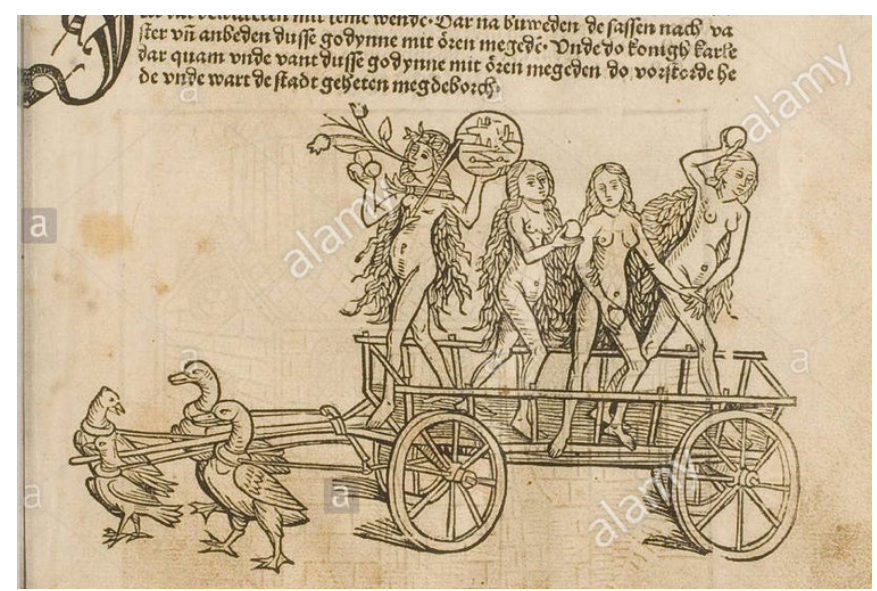

Figura 7. Conrad Bote (Konrad Botho). Illustrazione dal incunabulum: Cronecken der Sassen (As crônicas de Sassonia) Impresso por Peter Schöffer em Mainz, 1492, Augsburg. Fonte: Imagem de Domínio Público.

14 Para saber mais, recomenda-se a pesquisa de Chaudhuri, "The Chariot of Venus: A Note on Chapman's Mythographical Sources." (CHAUDHURI,
1981).
15 [tradução da autora]. 
Conclui-se que levando em consideração as referências textuais citadas, podemos facilmente interpretar a Taça da figura 3 como uma narrativa que retoma os poemas de Ovídio e a teogonia esiodea, oferecendo à figura do infante o lugar de personificação divina (Eros ou Adonis), e à frase presente na parte superior, "NON+E PRESA MIGLIOR", a possível tradução para a frase "não há caça melhor", aludindo tanto à flechada de Eros quanto ao passatempo de Adonis de caçar animais, que foi a causa de sua morte. Retomarei a questão da tradução ao falar do seu sentido para a Fortuna na próxima parte.

Será perceptível que a partir deste momento que elementos simbólico-narrativos em comum irão aparecer entre Vênus e Fortuna, principalmente ao considerarmos os estudos atentos de Aby Warburg nos arquivos florentinos, e no seu epistolário durante o período em Kreuzlingen.

\section{A FORTUNA E OCCASIO, OU A LEITURA WARBURGUIANA.}

...da riqueza inesgotável do arquivo florentino das coisas humanas, o pano de fundo da época pode ser reconstruído com clareza suficiente para que se possa corrigir historicamente uma consideração estética unilateral. ${ }^{16}$ (WARBURG, [1907] 1966.)

Ao contrário das leituras portuguesas, a imagem da figura 3 foi alocada na coleção de fotografias do arquivo londrino como relativa às representações da Deusa Fortuna. Isso ocorre devido a alguns fatores essenciais para a organização do acervo, a saber, os próprios estudos de Warburg sobre a Fortuna (WARBURG, 2014; WARBURG, 1966), e também, os decorrentes estudos iconológicos vinculados ao Instituto desde então, como os seguintes exemplos de artigos do Journal of the Warburg and Courtald Institutes (NELSON, 1980) ou livros publicados (GOMBRICH, 1972).

Em seus estudos sobre Francesco Sasseti (WARBURG, 1966), no Postscriptum à conferência de Doren (WARBURG [1923], 2014), e nos documentos presentes no instituto, elencados ao final do artigo como "Apêndice"17, a Deusa Fortuna de Aby Warburg é composta por elementos que a interpretam como forças do destino, virtudes, mas também como um monstrum, o equivalente da contraposição a Deus: "Francisco nem mesmo se esquiva da luta com a deusa pagã, aliás, no momento em que ela, encarnação do mundo inimigo, fica tangível diante dele como um vento sinistro e demoníaco, que pode agarrar e naufragar o navio de sua vida [...] ${ }^{18 "}$ (WARBURG, 1966, p.231) (figura 8).

\footnotetext{
16 [tradução da autora].

17 Visto a extensa lista de documentação, o elenco de documentos e suas respectivas catalogações encontram-se como "apêndice", após as referências bibliográficas.

18 [tradução da autora].
} 


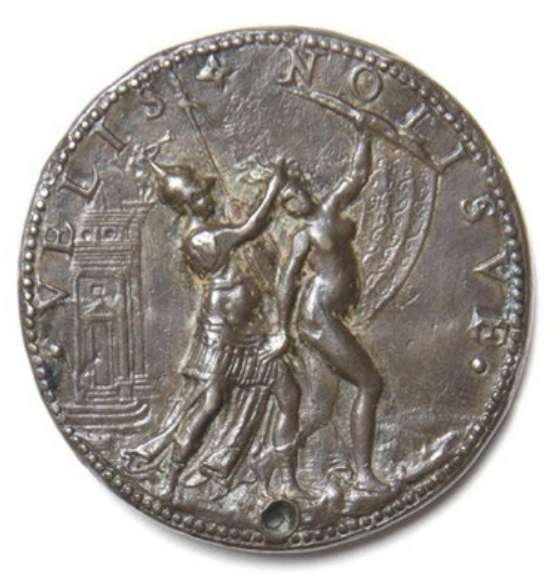

Figura 8. Giovan Battista Bonini. Medalha de Camillo Agrippa. 1580 ca. Fonte: The British Museum (online)

Nesta linha interpretativa, podemos encontrar o importante percurso proposto para o estudo do Painel 48 do Atlas Mnemosyne de Warburg organizado pelo Seminario Mnemosyne (2011). O exercício de pesquisa desta comunidade de intérpretes aprofunda os estudos de Warburg, buscando os elementos que distinguem as formas de figurar a Fortuna na Antiguidade, Medioevo e Renascimento, expondo em detaIhes e fontes imagéticas a leitura warburguiana acerca da deusa.

Como exemplo de leitura, em seu epistolário encontramos a carta a E. Seligman, em 1927 (Cfr. Apêndice), a ver:

\begin{abstract}
Na Fortuna com a franja/tufo de cabelo [il ciuffo], que encontrou no Occasio do Renascimento (ver Maquiavel) sua cunhagem derivada de uma representação antiga - Kairòs - é, ao contrário, o homem que tenta agarrar o destino pelo tufo e tomar posse firme de sua cabeça como presa, como o carrasco faz com a cabeça da vítima. Entre as duas, destaca-se a Fortuna com a vela, a qual também deriva de uma representação antiga, pois mesmo entre os Romanos a deusa da fortuna está na roda do leme/timão, e como Ísis Euploia, com a vela desenrolada, é a deusa da boa navegação [...] (WARBURG, 1927, s.n. $)^{19}$
\end{abstract}

Decididamente importante enquanto temática de estudo - e, deste modo, para a organização do material em sua biblioteca -, sua coleção de imagens acerca da Fortuna possivelmente acumulava no momento de sua morte um número representativo, a qual, transferida para Londres, continuou a fazer parte dos estudos iconológicos do instituto e da catalogação da Photographic Collection desde os anos $1930^{20}$.

Provavelmente, o desalinhamento entre as leituras iconográficas foi um dos principais motivos da ausência de informações sobre a obra e, também, da dificuldade em encontrar outra descrição compatível - e talvez uma possível atribuição de autoria.

Apesar do que à primeira vista parecem elementos em comum, vemos outros aspectos que evidenciam diferença entre as narrativas, em particular a figura femi-

\footnotetext{
19 [tradução da autora], conferir "apêndice".

20 É possivel pesquisar no Database quais imagem vieram da biblioteca hamburguesa. Encontram-se disponíveis mais de 5000 imagens vindas da Alemanha em 1933. Link de acesso:
} 
nina segurada pelos cabelos, e uma nova compreensão da frase "NON+E PRESA MIGLIOR". Primeiramente, podemos retomar a interpretação da Fortuna renascentista que é segurada pelo homem de virtude pelos cabelos (tufo) - o homem que controla seu destino), que, como sabemos pelos escritos de Warburg e pelas imagens de Cesare Ripa (1593 [figura 9]), tem paralelo com a imagem de Occasio, personificação do destino. A frase do Esmalte, neste contexto, parece compor uma leitura mais plausível: "não existe presa/captura melhor", remetendo novamente à iconologia da Fortuna-Destino que pode ser controlado pelos homens. Importante destacar, porém, que a frase é escrita de forma que elementos do latim estejam presentes, mas talvez haja a influência de um dialeto francês ou italiano na composição.

\section{Parte Prima. $\quad 255$}

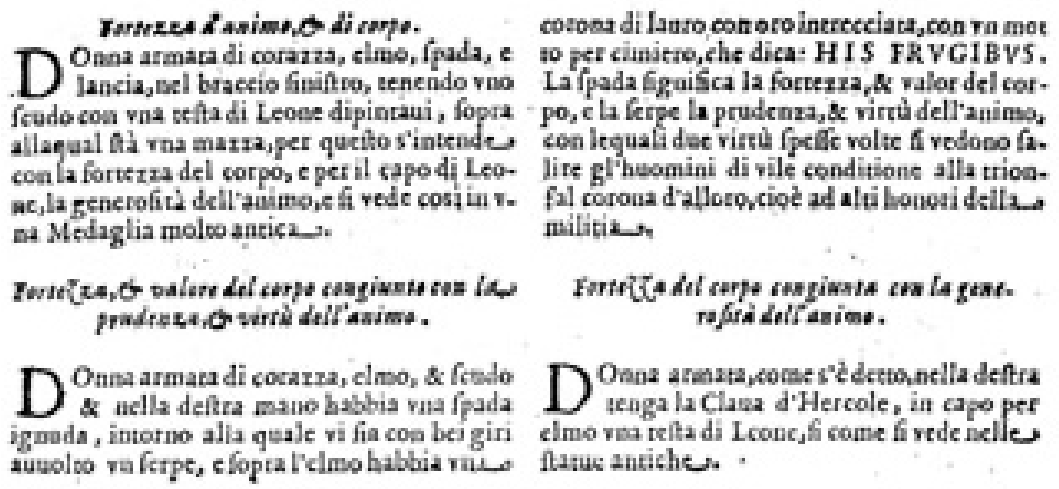

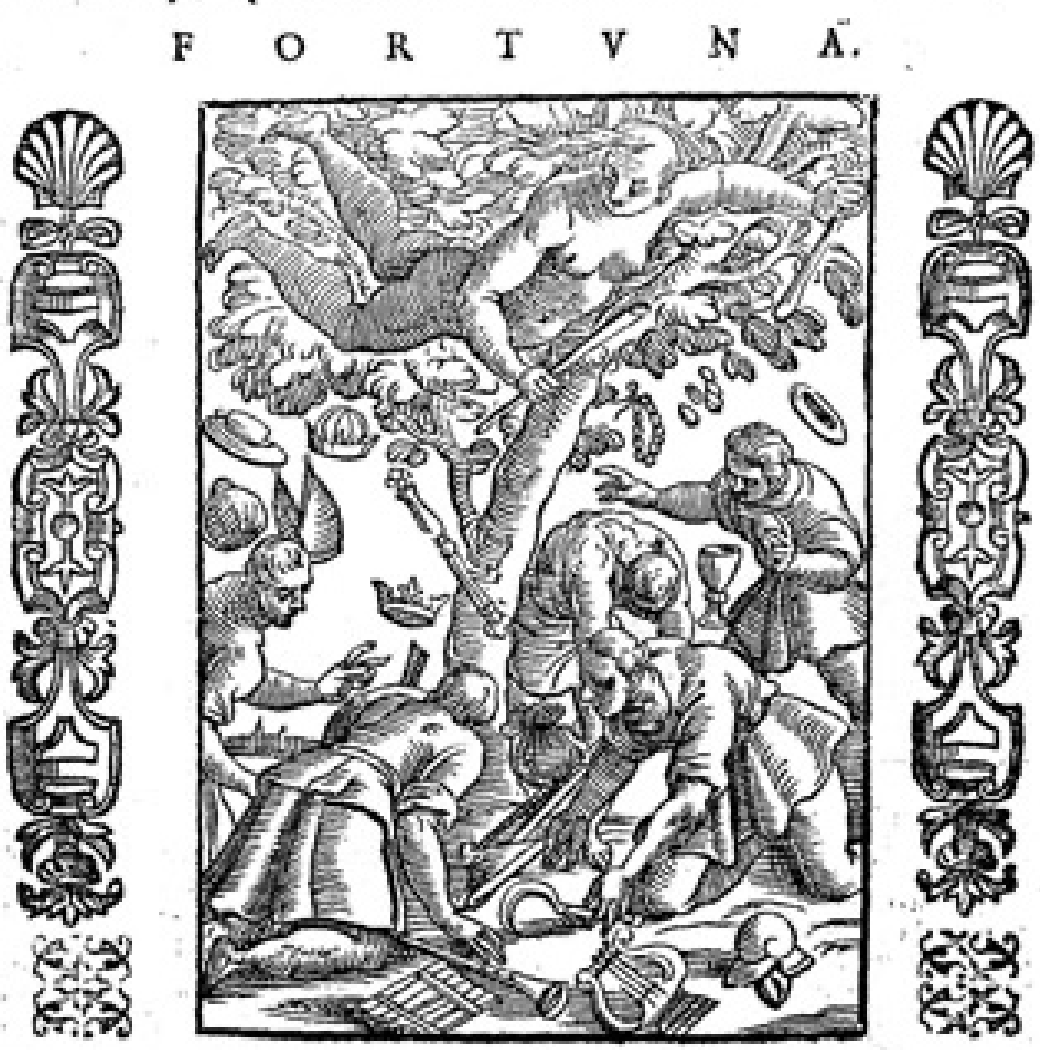

DONNA

Figura 9. Cesare Ripa. Página de L'Iconologia di Cesare Ripa. Ref:"Fortuna". p,255. 1593. Fonte: Imagem em dominio público. 
De tal modo, embora os textos portugueses a descrevam como Vênus a partir de elementos como o mar, estes também podem servir de base para leituras em prol da identificação da Fortuna. Botticelli usa a alegoria de Marziano Capella dos rios da Fortuna el De Nuptiis como fonte de inspiração para sua Primavera (Seminario Mnemosyne, 2011). Representações de "Fortuna-Vênus", como as de Andreas Cratander e a gravura em cobre de 1502 de Albrecht Dürer chamada de Grande Fortuna (Ibidem, 2011) vêm da região nórdica e tiveram sua influência em Limoges. E por fim, a pintura de Reni intitulada Fortuna representa uma "alegoria da "fortuna amorosa" - uma Vênus nua que deixa panejamento e cabelos soltos ao vento, enquanto um pequeno Amor [Cupido ou Erotes] alado a persegue e a captura" (Ibidem, 2011). Consequentemente, não é surpreendente que entre variações e continuidades seja possível falar no tema "Vênus-Fortuna" como um caminho temático. Como constantemente acontece com um tema da tradição clássica, a experiência de tratá-lo entre textos e imagens não pode evitar o entrelaçamento das linguagens/traduções ao longo dos séculos, estudando-se, portanto, "os mecanismos, as funções, os modos da transmissão dos textos e das imagens, da antiguidade greco-romana aos dias atuais" (CENTANNI, 2005. p.I) ${ }^{21}$.

\section{SENTIDOS E SIGNATURAS DO ARQUIVO}

À luz dessas considerações, algumas questões historiográficas e arquivísticas podem ser exploradas. A coleção de fotografias do Warburg Institute é constituída, antes de tudo, por aquilo que Agamben chamará de signaturas, relações entre a dimensão material do arquivo, dos registros físicos, e a dimensão imaterial, subliminal, da imagem. São signaturas do olhar daqueles que, a partir de Warburg, deram sentido as imagens presentes.

No acervo, várias séries de exemplos temático-iconográficos servem para apoiar as variações entre Vênus e Fortuna nos ornamentos dos séculos XV-XVI entre a França e a Itália. Consequentemente, pode-se identificar também na coleção a relação suscitada por Dias (Ibidem) entre o Milieu dos artistas de Limoges e os temas em voga nas pinturas desde o início do Renascimento italiano. Encontramos entre as imagens variadas fotos de Esmaltes: Obras de Urbino, Florença, Veneza e Roma; temas figurados por Dürer, Botticelli, Michelangelo, Raphael e possivelmente outros. Entre os artistas, foi possível localizar obras do legado de Nicola da Urbino, Reymond, Fontana, Durantino, Niccolò Pénicaud, De Court, Giorgio Andreoli, Manara, Calamelli, até Pierre ou Couly (Colin) Nouailher (DATABASE, 2021). Em outras palavras, algumas obras de relevância encontram-se fotografadas na coleção do Warburg Institute, ao mesmo tempo que as coleções mais importantes de esmaltes de Limoges encontram-se fisicamente nas coleções Frick, Metropolitan Museum, Walters Art Museum, Sothesby, Victoria \& Albert Museum, Los Angeles County Museum, Bargello National Museum of Florence e o Museu Nacional Adrien Dubouché, em Limoges.

21 [Tradução da autora]. 
Carlos Dias, ainda em suas Cartas, comenta que

a todas as collecções, tanto officiaes como particulares, sobreleva em raridade e riqueza a da casa Palmella, superior á que o barão Fernando Rothschild legou, em 1898, ao British Museum e considerada como uma das mais celebres da Europa, não tanto pelo número das peças que a compunham [entre 25 e 30], como pela sua beleza excepcional. [grifo meu]. (DIAS, Ibidem, p.43).

Desta forma sabemos que a coleção Palmella chega aos museus londrinos mediante uma doação com intuito conservacionista, reafirmando a ligação entre a imagem encontrada em Londres, e a descrição em Lisboa. Também podemos imaginar que entre artistas e famílias citadas pelo catálogo português e pelas cartas de Dias, poderia estar o autor desconhecido da obra. Abre-se aqui uma última experiência desta pesquisa, a nova e velha pesquisa histórica morelliana, indiciária, incompleta, e vale dizer, estética, para a qual todo um novo artigo merece ser publicado: quais as contribuições atuais que a pesquisa de matriz iconológica pode trazer, na busca pela atribuição de autoria desta obra e desta imagem? O que há para dizer, dois séculos depois de Morelli, acerca os arquivos virtuais e as imagens contemporâneas? E ainda, que tipos de saberes a iconologia, vista como experiência estética, pode conduzir, imagem por imagem? acervo por acervo? coleção por coleção?

Ainda que sugerir a atribuição da obra não tenha sido o intuito desta experiência de pesquisa, é interessante considerar que a iconologia de matriz warburguiana continua a possibilitar traçar rotas de transmigrações das imagens, e assim, a fazer correlações lá onde a imagem parecia ter sucumbido ao tempo e à memória. Continua, em um léxico próprio da "disciplina", a fazer-nos experimentar seu Atlas Mnemosyne, sua ideia de Wanderung das imagens, e seu exercício mnemotécnico e epistemológico.

Por isso, a problemática de atribuição, ou seja, essa busca genealógica, toca por fim na mesma questão levantada pelos trajetos de pesquisa iconológica da obra: a compreensão de que "toda imagem tem índices de associação potencialmente ilimitados que permitem a construção de séries texto-icônicas de tipo variado" (ROMANDINI, 2017, p.78), a contar da combinação de forças entre Epidosis e Paradosis da tradição clássica. Ambos os estudos derivam da imanência própria das imagens: sua dinâmica, seu movimento, sua função mnemônica, que ela "não pode, enquanto arte da memória, deixar de aglutinar." (ANTELO, 2010, 11).

E é aqui, por fim, que retomamos o sentido da operação historiográfica como, por um lado, uma prática marcada por experiências linguísticas e estruturada em sistematizações histórico-temporais. Por outro lado, no que se refere ao estudo das imagens artísticas, vemos esta operação se transformar em uma experiência estética e estésica, que pode engatilhar as mais diferentes respostas cognitivo-sensoriais, dada a obsessão das imagens em sempre conduzir (do lat. producĕre) novas relações, em nos levar à novas velhas imagens. 


\section{REFERÊNCIAS}

ANTELO, Raúl. Potências da imagem. Chapecó: Argos, 2004.

BARALE, A. SQUILLARO, L. Regesto di testi inediti e rari dal Warburg Institute Archive sul tema della Fortuna. La Rivista di Engramma, n. 92, agosto 2011.

BEYSSI-CASSAN, M. Le métier d'émailleur à Limoges: XVle-XVIle siècle. Thèse soutenue à l'Ecole Pratique des Hautes Etudes, Paris 2003 [2004].

Catalogo illustrado, Exposição Retrospectiva de Arte Ornamental Portuguesa e Hespanhola celebrada em Lisboa em 1882 sob a protecção de Sua Majestade el-Rei o Senhor D. Fernando II. Acervo Biblioteca Nacional de Portugal BNP, 2 volumes, Lisboa 1882.

CENTANNI, Monica (a cura di). L'originale assente. Introduzione allo studio della tradizione classica. Milano: Bruno Mondadori, 2005.

CHAUDHURI, Supriya. The Chariot of Venus: A Note on Chapman's Mythographical Sources. Journal of the Warburg and Courtauld Institutes, vol. 44, 1981, pp. 211-213. JSTOR, www.jstor.org/stable/751071. Acessado em 28/02/2021.

DATABASE, 2021. Iconographic Database. The Warburg Institute Iconographic Database. Link: https://iconographic.warburg.sas.ac.uk/vpc/VPC_search/main_page.php. Acesso em: 28/02/2021.

DIAS, Carlos M. Cartas de Lisboa, segunda serie, Lisboa: s. ed, 1905.

DIDI-HUBERMAN, G. Ninfa fluida: essai sur le drapé-désir. Paris: Gallimard, 2015.

ECO, Umberto. Pós-escrito In: O Nome da Rosa. Tradução de Letizia Zini Antunes e Álvaro Lorencini. Rio de Janeiro: Nova Fronteira, 1985.

GOMBRICH, E. H. Symbolic Images. Studies in the art of the Renaissance. Londres: Phaidon Press, 1972.

HIGGOTT, Suzanne. Wallace Collection Catalogues: glass and Limoges painted enamels. The Wallace Collection. Londres: Paul Holberton Publishing, 2011.

MUELA, Juan Carmona. Iconografía Clásica. Madrid: Ediciones istmo; Akal, 2000.

NELSON, A. H. Mechanical Wheels of Fortune, 1100-1547. In: Journal of the Warburg and Courtauld Institutes, Vol.43 (1980), pp-227-233. The Warburg Institute; JSTOR, 1980. 
NIETZSCHE, F. Segunda consideração intempestiva: da utilidade e desvantagem da história para a vida. Trad. Marco A. Casanova. Rio de Janeiro: Relume Dumará, 2003.

ROMANDINI, F. L. A Ascensão de Atlas. Glosas sobre Aby Warburg. Trad. F. de Carli. Florianópolis, 2017.

SANTOS, A. P. M. Esmaltes de Limoges e Peninsulares em Portugal da época Medieval à época Moderna. Tese de Doutoramento em História da Arte Portuguesa. Porto 2016.

SAPIENZA, Goliarda Sapienza. Ancestrale. Milano: Lavita felice, 2013.

SEMINARIO MNEMOSYNE, A cura di Id. Fortuna nel Rinascimento. Una lettura di Tavola 48 del Bilderatlas Mnemosyne. In: La Rivista di Engramma 92, agosto 2011. Link de acesso: http://www.engramma.it/eOS/index.php?id_articolo=1649 Acesso em: 20/01/2021.

Sotheby's Catalog. PRIVATE COLLECTOR. Attributed to Colin Nouailher. TAZZA WITH AN ANGEL FEEDING A PROPHET, PROBABLY ISAIAH. Limoges, circa 1530-1550. Londra, 2015. Link de acesso: https://www.sothebys.com/en/auctions/ecatalogue/2015/ old-master-sculpture-works-art-l15231/lot.82.html Acesso em: 28/02/2021.

SAXL, F. Lectures. London: The Warburg Institute, 1957.

TONIN, T. Eredità e Nachleben: L'opera e la fortuna Critica di Aby Warburg negli studi storico-artistici. La prospettiva iconologica e il valore mnemonico delle immagini. Tesi di Dottorato. Settore Scientifico Disciplinare: museologia e critica artistica e del restauro (m-sto/04) e storia contemporanea (l-art/04). Università Degli Studi Della Basilicata (DICEM): Matera, 2019.

VAN STRATEN, Roelof. Introduzione all'iconografia. Milano: Jaca Book SpA, 2009.

SEZNEC, Jean. La sopravvivenza degli antichi dei. Saggio sul ruolo della tradizione mitologica nella cultura e nell'arte rinascimentali. Torino: Bollatti Boringhieri, 2015.

VERDIER, Ph. The Taft Museum European. Decorative Arts, New York 1995.

WARBURG, A. Le ultime volontà di Francesco Sassetti. In: La rinascita del paganesimo antico, a c. di G. Bing, tr. it. di E. Cantimori, Firenze: Nuova Italia (1 edizione) 1966 [1907].

WARBURG, A. Per monstra ad sphaeram. A cura di D. Stimilli e C. Wedepohl. Milano: Abscondita, 2014 [1923-1925]. 
WARBURG, A. Frammenti sull'espressione. A cura di Susanne Muller. Pisa: Ed. della Normale Superiore di Pisa, 2011.

WIND, Edgar. Warburg's Concept of Kulturwissenschaft and its Meaning for Aesthetics. In: PREZIOZI, Donald (ed.). The Art of Art History. A Critical Anthology. New York: Oxford University Press, 2009.

\section{APÊNDICE}

Relação de fragmentos e textos encontrados no The Warburg Institute Archive acerca do tema Fortuna. Informações sobre acesso ao material estão disponíveis em: https://warburg.sas.ac.uk/library-collections/warburg-institute-archive

Localização: [WIA, III.85.3.4] e [85.3.3].

WARBURG, A. Fragmento sobre Lorenzo Spirito, 1913. Documento datiloescrito com anotações manuscritas do autor.

Localização: [WIA, III.93.14.2]

WARBURG, A. Cópia da carte de Goethe a Herder, de julho de 1772. Catalogada em janeiro-setembro de 1924. Documento datiloescrito.

Localização: [WIA, GC/12740]

WARBURG, A. Carta de Warburg Alfred Doren (Alfresco), de 31 de março de 1923). Documento datiloescrito.

Localização: [WIA, GC/19326]

WARBURG, A. Carta de Warburg a Edwin Seligman, de 17 de agosto de 1927. Documento datiloescrito.

Localização: [WIA, GC/21048]

WARBURG, A. Carta de Warburg a Adolf Goldschmid, de 11 de abril de 1929. Documento datiloescrito.

Localização: [WIA, GC/14586]

SAXL, F. Carta de Saxl a Warburg, de 27 de novembro de 1923. Documento datiloescrito.

Localização: [WIA, GC/30005]

URTEL, H. Carta de Urtel a Warburg, de 2 de março de 1924. Documento datiloescrito.

Localização: [WIA, GC/21048]

WARBURG, A. Carta de Warburg a Adolf Goldschmidt, de 11 de abril de 1929. Documento datiloescrito. 
Outros ensaios ou fragmentos do autor, traduzidos ao italiano:

WARBURG, A. Postscriptum alla conferenza di Alfred Doren "Fortuna nel medioevo e nel Rinascimento" ottobre 1923. In: Per Monstra ad Sphaeram. La conferenza in memoria di Franz Boll e altri scritti (1923-1925), a c. di. D. Stimilli e C. Wedepohl, tr. it. di D. Stimilli. Milano: Abscondita, 2014.

WARBURG, A. Le forze del destino riflesse nel simbolismo all'antica. Pensieri sulla funzione polare dell'antichità (Antike) nella trasformazione energetica della personalità europea nell'epoca del Rinascimento, aprile 1924. In: Per Monstra ad Sphaeram. La conferenza in memoria di Franz Boll e altri scritti (1923-1925), a c. di. D. Stimilli e C. Wedepohl, tr. it. di D. Stimilli. Milano: Abscondita, 2014.

Regesto di testi inediti e rari dal Warburg Institute Archive sul tema della Fortuna. a cura di A. Barale e L. Squillaro. La Rivista di Engramma n.92, agosto 2011. 